\title{
PLANEJAMENTO DAS AÇÕES DE MANEJO POPULACIONAL DE CÃES E GATOS NO MUNICÍPIO DE LENÇÓIS PAULISTA, SÃO PAULO
}

\author{
PLANNING OF MANAGEMENT ACTIONS FOR POPULATIONS OF DOGS AND \\ CATS IN LENÇÓIS PAULISTA, SÃO PAULO
}

\author{
A. P. ALMEIDA ${ }^{1 *}$, G. S. DE PAZ ${ }^{1}$, C. M. RIBEIRO ${ }^{1}$, F. N. GONÇALVES ${ }^{1}$, L. S. ROLIM ${ }^{1}$,
} T. PIGOSSI ${ }^{1}$, J. R. MODOLO ${ }^{1}$, C. VICTÓRIA ${ }^{1}$

\section{RESUMO}

O planejamento e execução de ações de manejo das populações de cães e gatos em áreas urbanas é um grande desafio para os gestores da saúde, pela falta de diagnóstico situacional relacionado à realidade da população destes animais no território urbano do município. São indicados três métodos para o controle populacional de cães e gatos: restrição da movimentação, controle do habitat e controle reprodutivo. As ações de educação permanente em saúde para a posse responsável de animais de estimação e a esterilização cirúrgica de cães e gatos são medidas indicadas como estratégias de controle populacional para essas espécies. Com base nestas afirmações, o objetivo do presente trabalho foi realizar um diagnóstico situacional do aspecto de castração dos animais levados aos postos de vacinação contra a Raiva, em 2013, na $18^{a}$ Campanha de vacinação anual contra a Raiva de cães e gatos de Lençóis Paulista/SP. Os dados foram obtidos a partir da ficha de cadastro de animais que foi utilizada na campanha de 2013, que continham campos para preenchimento de informações relacionadas à castração e à localização do proprietário. Com base nesses dados realizou-se a análise descritiva bem como a distribuição espacial dos resultados. O software ArcGIS $10.1^{\circledR}$ foi utilizado para elaboração dos mapas. Os resultados revelaram que a população de animais castrados representa apenas $7,14 \%$ do total de animais estimados para Lençóis Paulista. Na população felina, 42,88\% são castrados, enquanto que entre os cães, apenas 12,15\%. Em ambas as espécies, as fêmeas são as mais castradas, sendo o percentual de $52,23 \%$ para as gatas e $17,06 \%$ para as cadelas. O mapeamento pelas técnicas de geoprocessamento foi útil para que pudesse avaliar a distribuição dos animais castrados a fim de se planejar novas ações para aumento da cobertura destas atividades em todo o município.

PALAVRAS-CHAVE: POPULAÇÃO. REPRODUÇÃO. CASTRAÇÃO. GEOPROCESSAMENTO

ÁREA TEMÁTICA: Planejamento de Saúde Animal e Saúde Pública

\footnotetext{
${ }^{1}$ Faculdade de Medicina Veterinária e Zootecnia da Universidade Estadual Paulista (UNESP) - Campus de Botucatu

* arthurpombo_mv@hotmail.com
} 